\title{
Effects of intermittent negative pressure and active recovery therapies in the post-match period in elite soccer players: A randomized, parallel arm, comparative study
}

\author{
Alex Souto Maior ${ }^{1}$; Marcio Tannure ${ }^{2}$; Fábio Eiras², Arthur de Sá Ferreira $^{1}$ \\ 1 Master's and Doctorate Program in Rehabilitation Science at UNISUAM (Augusto Motta University Center), Rio de \\ Janeiro, Brazil; ${ }^{2}$ High Performance Center - Flamengo Soccer Club, Rio de Janeiro, Brazil
}

\section{Summary}

Study aim: This study compared the effects of intermittent negative pressure therapy (INPT) vs. active recovery therapy (ART) on post-match physiological parameters such as serum CK level and skin temperature of the lower limbs in elite soccer players.

Material and methods: Twenty healthy male professional soccer players from a Brazilian first division soccer club were enrolled in this randomized, parallel arm, open label, comparative study. After participating in 2 soccer matches, they were randomly assigned to two groups $(\mathrm{n}=10)$ to receive a 30 -min session of INPT (intermittent exchange of hypobaric pressure range 33 to $51 \mathrm{mmHg}$ ) or ART (self-myofascial release, mobility and stability exercises, and cycle ergometer exercise). The intervention was conducted after a match with assessments immediately before and after the intervention and again $24 \mathrm{~h}$ after the intervention.

Results: A significant interaction effect $\left(\mathrm{F}_{2,36}=4.503, \mathrm{p}=0.018, \eta^{2}=0.130\right)$ was observed, indicating that the decrease of CK from pre-intervention to $24 \mathrm{~h}$ post-intervention was greater in the INPT than in the ART group. Lower limb skin temperature was significantly lower after INPT than after ART $(\mathrm{p}<0.003)$.

Conclusions: Serum CK level and skin temperature of lower limbs showed better recovery up to $24 \mathrm{~h}$ after the intervention with INPT in elite soccer players.

Keywords: Creatine kinase - Thermal images - Soccer - Sports performance - Recovery

\section{Introduction}

Soccer matches are characterized by high-speed running while dribbling, passing, kicking or throwing the ball, with players required to make quick, precise movements, actions requiring multi-directional deceleration and acceleration, in addition to rapid changes of direction, all placing high demands on several physical components $[11,25]$. Thus, physical stress during training and/or match play prompts morphological, metabolic, and functional adaptations that consequently enable an increase in performance $[10,36]$. On the other hand, the stresses of both training and competition can causes temporary reductions in physical performance and post-match fatigue recovery, both being associated with an increased risk of musculoskeletal injury [25].
Exercise-induced muscle damage is characterized by a temporary decrease in maximal force-generating capacity, impaired physical performance, and increase in intracellular proteins in the blood, muscle soreness, and swelling in and around the involved muscle groups [18, 25, 31]. Up to $70 \%$ of soccer injuries occur in the lower limbs, typically during running, body contact, and eccentric muscle actions required when braking from sprints (deceleration) and landing from jumps, which cause a decline in physical performance lasting hours or days following a match $[18,33]$. The magnitude of physical stress on the skeletal muscle system can be inferred by measuring the plasma creatine kinase $(\mathrm{CK})$ and skin temperature by thermal images to determine changes in response to physiological processes or pathological reactions related to training and/ or matches $[18,25]$. Measuring the physical stress involving the implementation of single combined techniques is 
important to develop recovery strategies that might accelerate the time to achieve full recovery as well as reduce the risk of injury $[23,26]$.

The development of strategies to recover from physical stress in soccer players allows a better understanding of the physiological responses and injury prevention associated with training load and match intensity. For instance, cold water immersion and contrast water therapy $(88 \%$ of teams), active recovery therapy (ART) (81\%), massage (78\%), stretching (50\%), compression garments $(22 \%)$ and electrical stimulation (13\%) are among the most used strategies [14, 20, 28]. In addition, nutrition and hydration were considered as very effective recovery strategies by $97 \%$ of the practitioners, while sleep was also considered as an effective recovery strategy by $95 \%$ of practitioners [27, 32]. In particular, ART consists of maintaining submaximal work after matches with the aim of preserving performance level between matches. There are basically 3 active recovery techniques that are applied in soccer: self-myofascial release (muscle relaxation through mobilization and loosening of the limbs in pairs); mobility and stability exercise; low-intensity aerobic activity (jogging, cycling and/or deep-water running). Thus, exercises are used as a therapeutic tool to accelerate the recovery $[27,28]$. However, no study has investigated the relationship between intermittent negative pressure therapy (INPT) and post-match recovery in elite soccer players.

INPT is a technique that promotes negative pressure in the lower limbs. This device consists of a vacuumsealing cylindrical space in which the lower body (up until the waist) of a lying subject is enclosed. In the waist region, the inner space of the device is sealed by means of a lens and within the cylindrical space, a vacuum pump generates intermittent normal and low pressure (range 28 to $52 \mathrm{mmHg}$ ). INPT is a therapy used in wound treatment to increase granulation tissue formation, remove edema, stimulate a cell-mediated immune response, decrease blood vessel permeability, and stimulate angiogenesis and blood flow to the wound margins [5, 8, 19, 22]. Additionally, INPT promotes an increase in foot macro- and microcirculatory flow pulsatility and mean arterial blood flow velocity in patients with peripheral arterial disease [35]. Apparently, only one study has investigated INPT after exercise-induced muscle damage therapy in elite athletes; an attenuated loss of muscle strength and power along with decreased perception of pain in the group receiving 60 minutes daily INPT therapy was reported, but no changes in biochemical markers [15]. Therefore, this study compared the effects of INPT vs. ART in the post-match physiological parameters serum CK level and skin temperature of the lower limbs in elite soccer players. Our hypothesis was that INPT would improve the recovery from physical stress (changes in biochemical markers and thermal images) because it is a method of passive recovery, compared to the method of active recovery (ART).

\section{Materials and methods}

\section{Participants}

Participants were eligible if they were non-smokers (for the previous 3 months or more); had no cardiovascular or metabolic diseases, recent musculoskeletal injury (in the last 6 months), or pain in any region of the body; and had not used anabolic steroids, drugs or any medication with the potential to impact physical performance (self-reported).

This study included 20 healthy male elite soccer players from a club in Brazil participating in first-division national and international competitions organized by the Brazilian Soccer Confederation and South American Soccer Confederation. The participants were randomly divided into two groups to receive INPT $(n=10)$ or ART $(n=10)$. The participants' training frequency was $6.1 \pm 0.5$ days/week, with mean duration for each session training of $65 \mathrm{~min}$, using training programs consisting of jumps, contesting possession, sprints, accelerations and decelerations. All participants performed in 2 official matches for $87.4 \pm 9.3$ minutes interspersed by 4 days.

This study was approved by the institutional Ethics Committee for Human Experiments (CAAE: 76189817.0.0000.5235) and was performed in accordance with national standards in sport and exercise science research. All participants signed the informed consent form.

\section{Study design}

This is a randomized, parallel arm, open label, comparative study. The sample size was determined by including all participants enrolled in the soccer matches who complied with the eligibility criteria. The intervention was conducted $24 \mathrm{~h}$ after a match with assessments immediately before and after the intervention and again $24 \mathrm{~h}$ after the intervention. Five athletes were submitted randomly to INPT 24 hours after the first match and five athletes submitted to INPT 24 hours after the second match. All measurements occurred between 8:00 and 9:00 A.M. in a quiet and temperature-controlled environment (temperature $21^{\circ} \mathrm{C}, 65 \%$ relative humidity) by a Hygro-Thermometer with Humidity Alert (Extech Instruments, Massachusetts, EUA) to allow participants to obtain their thermoneutral zone and to reduce sympathetic stress that could create artifacts [34]. The equilibration period to evaluate skin temperature was set at 15 minutes. Data collection was performed prior to scheduled training sessions by a panel of examiners blinded to each other's results. Coffee, tea and alcohol intake was prohibited for four hours before measurements. Also, the participants refrained from 
physiotherapy (e.g. massage, electrotherapy, ultrasound, heat treatment, cryotherapy, hydrotherapy) before any measurements and did not apply cosmetic products to the skin to obtain meaningful readings of skin temperature by thermal images.

\section{Anthropometric measurements}

Body composition was measured following an 8-h overnight fast by bioelectrical impedance analysis using a device with built-in hand and foot electrodes (InBody 720 , Biospace, Korea; inbody.com). The participants wore their normal indoor clothing and were instructed to stand bare-foot in an upright position with both feet on separate electrodes on the device's surface and with their arms abducted and both hands gripping two separate electrodes on each handle of the device.

\section{Training load monitoring and global position system (GPS)}

During two official matches, the movement of all soccer players was monitored and quantified by means of portable global position system (GPS) devices (Mini$\max X$, v.4.0, Catapult Innovations; Australia) operating at a sampling frequency of $10 \mathrm{~Hz}$ and incorporating a $100 \mathrm{~Hz}$ triaxial accelerometer. Each player wore a special harness enabling the device to be fitted to the upper part of his back. The GPS devices were activated $10 \mathrm{~min}$ prior to the start of each official match in accordance with the manufacturer's instructions. After each match, GPS files were downloaded to a computer and analyzed using the software provided by the manufacturer (Logan Plus Version 4.2.3, Melbourne, Australia). The participants' data were excluded from the analysis if they failed to complete any match due to injury and/or substitution.

The GPS devices used in the current study did not delineate forward, backward, or lateral directions, with all movement being considered universal. The indicators of the external load were as follows: 1) total distance covered; 2) frequency of efforts $\geq 18 \mathrm{~km} / \mathrm{h}$ ); 3) frequency of efforts $\geq 24 \mathrm{~km} / \mathrm{h} ; 4$ ) maximal speed during matches. In addition, data obtained combining accelerations produced in three planes of body movement by means of a $100 \mathrm{~Hz}$ triaxial accelerometer within the GPS device were used to classify the external training load using the player-load equation. Player-load is used as an indicator of the external load because acceleration is proportional to force and may provide a useful measure of the total load applied to a player within a match [12]. Player-load was calculated by Logan Plus software using the following equation:

$$
(a y 1-a y-1)^{2}+(a x 1-a x-1)^{2}+(a z 1-a z-1)^{2},
$$

where $a y=$ antero-posterior acceleration, $a x=$ medio-lateral acceleration, and $a z=$ vertical acceleration.

\section{Intermittent negative pressure therapy (INPT)}

The INPT group was exposed to the intervention according to the manufacturer's recommendations and the protocol described in Table 1. The participants were comfortably clothed and seated for 15 minutes before the experiment started. In sequence, they were taken to the vacuum chamber with internal padding to allow insertion of both legs before sucking the air out of the bag and creating a hypobaric environment (Vacusport; Weyergans High Care, Dueren, Germany) (Fig. 1). Each therapy lasted for 30 minutes and consisted of intermittently exchanging of hypobaric pressure in the range 33 to $51 \mathrm{mmHg}$. Pressures were continuously monitored throughout the study using a calibrated pressure probe attached to the vacuum cham-

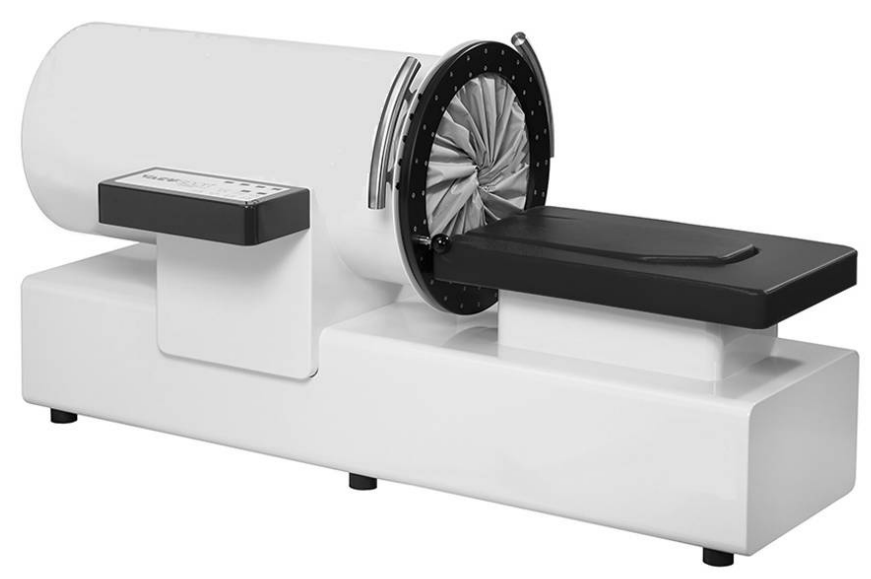

Fig. 1. Equipment utilized to intermittent negative pressure therapy (INPT)

Table 1. Description of the intermittent negative pressure therapy protocol

\begin{tabular}{lcccc}
\hline Phases & Time of negative pressure [s] & Intervals [s] & Exposure time of each phase [min] & Negative Pressure [mmHg] \\
\hline$\# 1$ & 8 & 6 & 6 & 33 \\
$\# 2$ & 6 & 8 & 6 & 40 \\
$\# 3$ & 9 & 6 & 6 & 46 \\
$\# 4$ & 6 & 9 & 6 & 51 \\
$\# 5$ & 9 & 9 & 6 & 43 \\
\hline
\end{tabular}


ber, which provides the values through the equipment's display.

\section{Active recovery therapy (ART)}

Participants underwent an ARC protocol for 30 minutes 24 hours after the match. ART was divided into three moments: 1) a foam roller (FR) with dimensions of $6.25 " \times 6.25 " \times 20.25 "$ (SKLZ, CA, USA) was applied over anterior-posterior regions of the thighs and legs in both lower limbs for 4 sets of $20 \mathrm{~s}$ in each region of interest with a 20 -s rest period between sets. The participants started at the proximal region of the thighs and legs and rolled down toward to the distal region. All participants were instructed to utilize their body mass over the thighs and legs with the help of the arms to make the movement and speed was controlled by a metronome ( $2 \mathrm{~s}$ per pass); 2) all participants conducted a 10-min mobility and stability exercise regime comprising multiple sets (i.e., 2-3 sets) from static movements to dynamic movements and finally a combination of these. The exercise program involved muscular activation of lower limb and trunk muscles using five exercises for anterior-posterior regions (i.e., prone planks; shoulder bridges; single leg deadlift with body weight; side brides; and sidestep with elastic resistance around the thighs in a squatting position) with 10-15 s contraction time (isometric condition) and 8-10 repetitions (dynamic condition); and 3 ) active recovery using a cycle ergometer $(60 \mathrm{rpm}, 80 \mathrm{~W})$ for 10 minutes. The ART protocol was supervised by a physical trainer with more than 10 years of experience.

\section{Measurement of plasma CK}

Plasma CK monitoring was assessed by reflectance photometry at $37^{\circ} \mathrm{C}$ using a previously calibrated device (Reflotron Plus; Roche, Germany) following the manufacturer's instructions. After sterilizing the finger using 70\% ethyl alcohol, a disposable lancet with an automatic trigger was used to puncture the fingertip and blood was drained into heparinized capillary strips for analysis. A $32 \mu \mathrm{L}$ sample of blood was immediately pipetted into a CK test strip and inserted into the analyzer. Absolute values of CK were used for analysis.

\section{Measurement of skin temperature}

Thermal image sequences of the lower limbs (thighs, legs, and knee) were acquired from both anterior and posterior views by a digital infrared thermo-camera (Flir Systems Inc, model T-540, USA; measurement range of $20^{\circ} \mathrm{C}$ to $1500^{\circ} \mathrm{C}$; accuracy of $\pm 2^{\circ} \mathrm{C}$ or $2 \%$; sensitivity of $\leq 0.05^{\circ} \mathrm{C}$ ), with an infrared spectral band from 7.5 to 14 microns, a refresh rate of $60 \mathrm{~Hz}$ and an FPA (focal plane array) of $464 \times 348$ resolutions for a total of 161.472 pixels. Figure 2 shows a representative thermal image from thighs and legs in both anterior and posterior views. The distance between the participants and the camera was standardized at 4 meters and the index of human skin emissivity was set to 0.98 . To analyze the thermal images body regions of interest (ROI) were selected by a drawing rectangular area using the software (Smartview3.1 - Fluke, Everett, USA), which provided both the average and maximum temperatures from each ROI [25]. Selection of the thigh

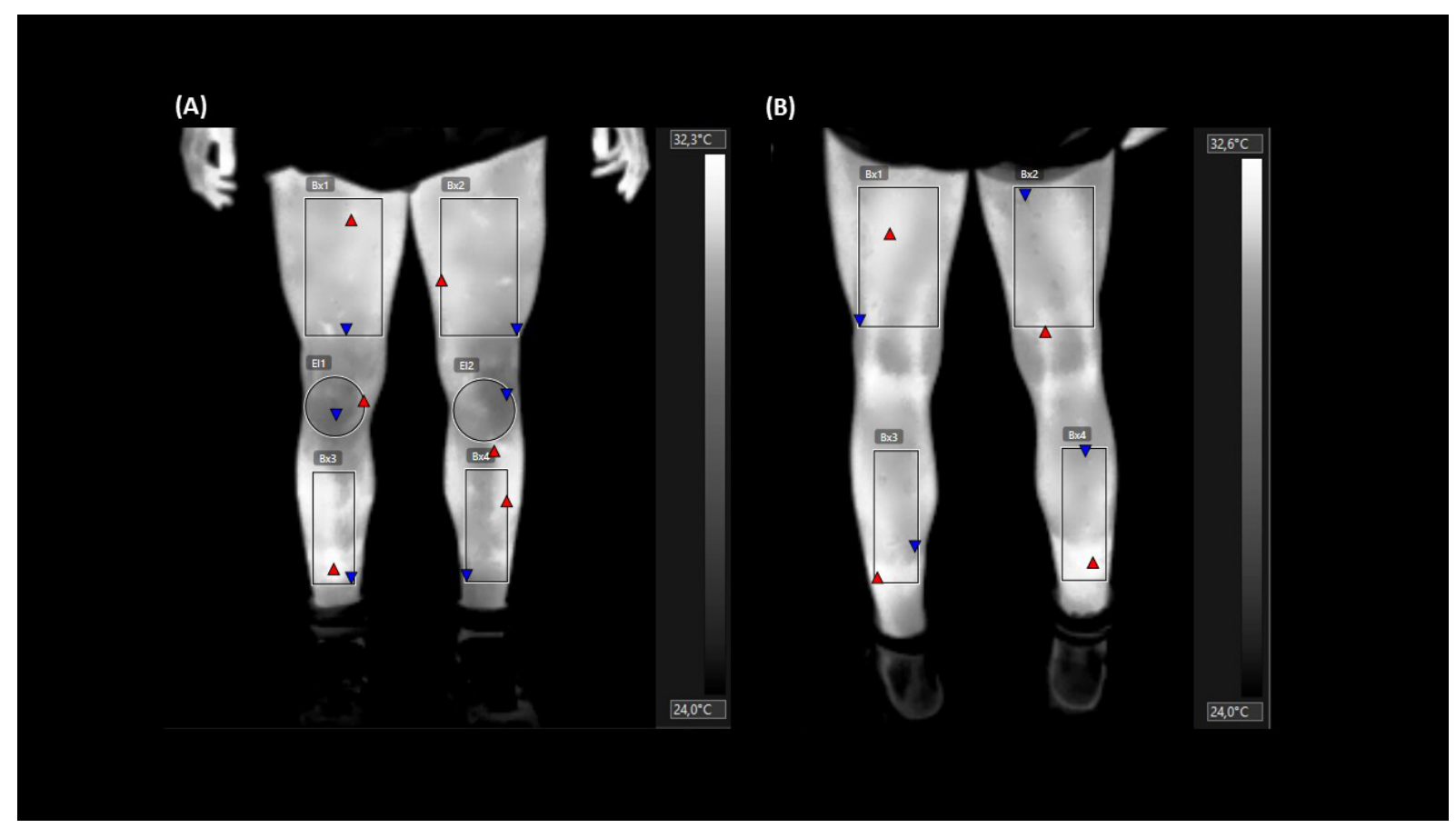

Fig. 2. Thermal images of the knee, anterior (A) and posterior (B) views from thighs and legs 
ROI utilized $5 \mathrm{~cm}$ above the upper border of the patella and groin line, whereas for the leg ROI we marked $5 \mathrm{~cm}$ below the lower border of the patella and $10 \mathrm{~cm}$ above the malleolus [25]; the knee ROI was defined around the patella.

\section{Statistical analysis}

Data were summarized as mean $\pm \mathrm{SD}$. Statistical analysis was initially performed using the Shapiro-Wilk normality test and the homoscedasticity test (Bartlett criterion). Student's t-test was used to assess differences in the indicators of the external load between matches (match \#1 vs. match \#2). Two-way analysis of variance (ANOVA) was used to test for main and interaction effects of group (levels: INPT, ART) and timing of measurement (levels: preintervention, post-intervention, $24 \mathrm{~h}$ post-intervention) for each outcome variable independently. Statistical analysis was performed with GraphPad (Prism 6.0, San Diego, CA, USA) software. The statistical significance level was set at $\mathrm{p}<0.05$ with Bonferroni post-hoc tests $(\mathrm{p}<0.003)$.

\section{Results}

Table 2 shows the baseline characteristics of participants. Age, height, bodyweight and body fat were not significantly different between groups (Table 2). Student's t-test (Table 3) showed no significant betweenmatch differences for total distance covered $(p=0.505)$,

Table 2. Baseline characteristics of the INPT and ART group

\begin{tabular}{lccc}
\hline Variables & INPT & ART & P value \\
\hline Age [years] & $20.4 \pm 3.7$ & $21.7 \pm 4.3$ & 0.4512 \\
Height $[\mathrm{cm}]$ & $178.5 \pm 6.2$ & $179.5 \pm 5.2$ & 0.5285 \\
Weight $[\mathrm{kg}]$ & $74.3 \pm 5.2$ & $73.8 \pm 6.2$ & 0.3334 \\
Body fat [\%] & $10.4 \pm 4.1$ & $10.8 \pm 4.6$ & 0.7938 \\
\hline
\end{tabular}

horizontal velocity $(p=0.278)$, frequency of efforts $\geq 18 \mathrm{~km} / \mathrm{h}(\mathrm{p}=0.181)$, frequency of efforts $\geq 24 \mathrm{~km} / \mathrm{h}$ $(\mathrm{p}=0.322)$, maximal speed $(\mathrm{p}=0.254)$, player load $(\mathrm{p}=$ $0.377)$, player load per minute $(\mathrm{p}=0.556)$ or total minutes $(\mathrm{p}=0.166)$.

The two-way ANOVA yielded main effects for group $\left(\mathrm{F}_{1,18}=6.969, \mathrm{p}=0.017, \eta^{2}=0.279\right)$ and for timing of measurement $\left(\mathrm{F}_{2,36}=12.248, \mathrm{p}<0.001, \eta^{2}=0.352\right)$, such that the CK concentration was significantly higher for ART than for INPT and decreased from pre-intervention to $24 \mathrm{~h}$ post-intervention. Post-hoc analysis showed that CK concentration significantly decreased from pre-intervention to 24-h post-intervention $(\mathrm{p}<0.001)$. Most importantly, the interaction effect was significant $\left(\mathrm{F}_{2,36}=4.503, \mathrm{p}=0.018\right.$, $\left.\eta^{2}=0.130\right)$, indicating that the decrease of CK from preintervention to $24 \mathrm{~h}$ post-intervention was greater in the INPT than in the ART group (Fig. 3).

Summary statistics for the effects of INPT and ART groups by timing of measurements are shown in Tables 4 and 5. The two-way ANOVA showed interaction effects group*timing for the maximum skin temperature

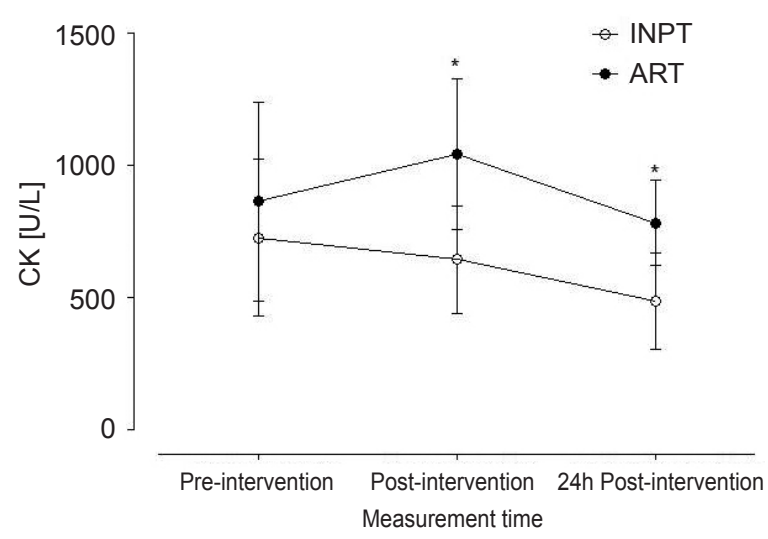

Fig. 3. Mean $\pm \mathrm{SD}$ values from serum $\mathrm{CK}$ level pre- and post-intervention and again $24 \mathrm{~h}$ post-intervention in elite soccer players. INPT: intermittent negative pressure therapy; ART: active recovery therapy. ${ }^{*} \mathrm{p}<0.01-$ INPT vs. ART

Table 3. Indicators of external load during match

\begin{tabular}{lccc}
\hline Variables & Match \#1 & Match \#2 & P value \\
\hline Total distance covered [m] & $8828 \pm 1323$ & $8419 \pm 1032$ & 0.5047 \\
Horizontal velocity [m/min] & $97.3 \pm 8.4$ & $91.4 \pm 12.9$ & 0.2775 \\
Frequency of efforts $\geq 18 \mathrm{~km} / \mathrm{h}$ & $55.8 \pm 19.3$ & $42.5 \pm 18.1$ & 0.1811 \\
Frequency of efforts $\geq 24 \mathrm{~km} / \mathrm{h}$ & $10.7 \pm 8.5$ & $8.2 \pm 4.8$ & 0.3222 \\
Maximal speed [km/h] & $31.6 \pm 3.5$ & $30.6 \pm 2.6$ & 0.2538 \\
Player Load (A.U.) & $840.3 \pm 117.1$ & $820.9 \pm 150.2$ & 0.3774 \\
Player Load per minute (A.U.) & $9.3 \pm 1.4$ & $9.7 \pm 1.6$ & 0.5559 \\
Total minutes & $88.6 \pm 9.2$ & $86.2 \pm 10.2$ & 0.1656 \\
\hline
\end{tabular}


Table 4. Maximal values of skin temperature $\left({ }^{\circ} \mathrm{C}\right)$ of thigh, leg, and knee in elite soccer players $(\mathrm{n}=10$ per group)

\begin{tabular}{|c|c|c|c|c|c|}
\hline Body regions of interest & & $\begin{array}{c}\text { Pre- } \\
\text { intervention }\end{array}$ & $\begin{array}{c}\text { Post- } \\
\text { intervention }\end{array}$ & $\begin{array}{c}24 \mathrm{~h} \text { Post- } \\
\text { intervention }\end{array}$ & Main and interaction effects \\
\hline \multirow[t]{3}{*}{ Anterior thigh left } & & & & & Interaction: $\mathrm{F}_{2,36}=4.404, \mathrm{p}=0.019, \eta^{2}=0.194$ \\
\hline & INPT & $32.7 \pm 0.7$ & $32.2 \pm 0.5$ & $32.6 \pm 0.7$ & Group: $\mathrm{F}_{1,18}=18.180, \mathrm{p}<0.001, \eta^{2}=0.503$ \\
\hline & ART & $33.3 \pm 0.8$ & $33.7 \pm 0.6$ & $33.6 \pm 0.7$ & Timing: $F_{2,36}=4.404, p=0.742, \eta^{2}=0.013$ \\
\hline \multirow[t]{3}{*}{ Anterior thigh right } & & & & & Interaction: $\mathrm{F}_{2,36}=7.542, \mathrm{p}=0.002, \eta^{2}=0.284$ \\
\hline & INPT & $32.7 \pm 0.8$ & $32.1 \pm 0.6$ & $32.5 \pm 0.7$ & Group: $\mathrm{F}_{1,18}=18.570, \mathrm{p}<0.001, \eta^{2}=0.508$ \\
\hline & ART & $33.1 \pm 0.5$ & $33.6 \pm 0.6$ & $33.6 \pm 0.7$ & Timing: $F_{2,36}=1.001, p=0.377, \eta^{2}=0.038$ \\
\hline \multirow[t]{3}{*}{ Posterior thigh left } & & & & & Interaction: $\mathrm{F}_{2,36}=1.807, \mathrm{p}=0.179, \eta^{2}=0.091$ \\
\hline & INPT & $32.6 \pm 0.8$ & $32.4 \pm 0.4$ & $32.3 \pm 0.5$ & Group: $F_{1,18}=24.750, p<0.001, \eta^{2}=0.579$ \\
\hline & ART & $33.1 \pm 0.7$ & $33.3 \pm 0.7$ & $33.4 \pm 0.3$ & Timing: $F_{2,36}=0.051, p=0.951, \eta^{2}=0.003$ \\
\hline \multirow[t]{3}{*}{ Posterior thigh right } & & & & & Interaction: $\mathrm{F}_{2,36}=1.749, \mathrm{p}=0.188, \eta^{2}=0.080$ \\
\hline & INPT & $32.8 \pm 0.6$ & $32.3 \pm 0.6$ & $32.3 \pm 0.4$ & Group: $F_{1,18}=20.680, p<0.001, \eta^{2}=0.535$ \\
\hline & ART & $33.4 \pm 0.9$ & $33.3 \pm 0.7$ & $33.5 \pm 0.4$ & Timing: $F_{2,36}=1.749, p=0.131, \eta^{2}=0.098$ \\
\hline \multirow[t]{3}{*}{ Anterior leg left } & & & & & Interaction: $\mathrm{F}_{2,36}=1.772, \mathrm{p}=0.003, \eta^{2}=0.249$ \\
\hline & INPT & $32.4 \pm 0.6$ & $31.5 \pm 0.5$ & $32.1 \pm 0.5^{*}$ & Group: $\mathrm{F}_{1,18}=63.31, \mathrm{p}<0.001, \eta^{2}=0.779$ \\
\hline & ART & $32.9 \pm 0.6$ & $33.1 \pm 0.5$ & $33.2 \pm 0.3^{*}$ & Timing: $\mathrm{F}_{2,36}=3.004, \mathrm{p}=0.062, \eta^{2}=0.107$ \\
\hline \multirow[t]{3}{*}{ Anterior leg right } & & & & & Interaction: $\mathrm{F}_{2,36}=7.697, \mathrm{p}=0.002, \eta^{2}=0.258$ \\
\hline & INPT & $32.6 \pm 0.7$ & $31.5 \pm 0.5$ & $32.2 \pm 0.4^{*}$ & Group: $\mathrm{F}_{1,18}=79.750, \mathrm{p}<0.001, \eta^{2}=0.816$ \\
\hline & ART & $33.0 \pm 0.7$ & $33.3 \pm 0.5$ & $33.4 \pm 0.3^{*}$ & Timing: $\mathrm{F}_{2,36}=4.143, \mathrm{p}=0.024, \eta^{2}=0.139$ \\
\hline \multirow[t]{3}{*}{ Posterior leg left } & & & & & Interaction: $\mathrm{F}_{2,36}=2.143, \mathrm{p}=0.132, \eta^{2}=0.086$ \\
\hline & INPT & $32.3 \pm 0.7$ & $31.4 \pm 0.7$ & $32.2 \pm 0.5^{*}$ & Group: $\mathrm{F}_{1,18}=13.930, \mathrm{p}=0.002, \eta^{2}=0.436$ \\
\hline & ART & $32.5 \pm 0.7$ & $32.5 \pm 0.8$ & $32.9 \pm 0.4^{*}$ & Timing: $\mathrm{F}_{2,36}=4.876, \mathrm{p}=0.013, \eta^{2}=0.195$ \\
\hline \multirow[t]{3}{*}{ Posterior leg right } & & & & & Interaction: $\mathrm{F}_{2,36}=4.200, \mathrm{p}=0.023, \eta^{2}=0.153$ \\
\hline & INPT & $32.4 \pm 0.6$ & $31.5 \pm 0.6$ & $32.2 \pm 0.4^{*}$ & Group: $\mathrm{F}_{1,18}=18.660, \mathrm{p}<0.001, \eta^{2}=0.436$ \\
\hline & ART & $32.6 \pm 0.4$ & $32.6 \pm 0.8$ & $32.8 \pm 0.4^{*}$ & Timing: $\mathrm{F}_{2,36}=5.243, \mathrm{p}=0.010, \eta^{2}=0.191$ \\
\hline \multirow[t]{3}{*}{ Anterior knee left } & & & & & Interaction: $\mathrm{F}_{2,36}=1.000, \mathrm{p}=0.378, \eta^{2}=0.049$ \\
\hline & INPT & $31.8 \pm 0.9$ & $31.5 \pm 0.6$ & $31.7 \pm 0.5$ & Group: $\mathrm{F}_{1,18}=20.070, \mathrm{p}<00.001, \eta^{2}=0.527$ \\
\hline & ART & $32.4 \pm 0.8$ & $32.4 \pm 0.5$ & $32.8 \pm 0.5$ & Timing: $\mathrm{F}_{2,36}=1.514, \mathrm{p}=0.234, \eta^{2}=0.074$ \\
\hline \multirow[t]{3}{*}{ Anterior knee right } & & & & & Interaction: $\mathrm{F}_{2,36}=0.733, \mathrm{p}=0.487, \eta^{2}=0.037$ \\
\hline & INPT & $31.6 \pm 1.0$ & $31.4 \pm 0.8$ & $31.6 \pm 0.9$ & Group: $\mathrm{F}_{1,18}=15.000, \mathrm{p}<0.001, \eta^{2}=0.455$ \\
\hline & ART & $32.3 \pm 0.9$ & $32.4 \pm 0.5$ & $32.8 \pm 0.4$ & Timing: $F_{2,36}=0.902, p=0.415, \eta^{2}=0.046$ \\
\hline
\end{tabular}

INPT: intermittent negative pressure therapy; ART: active recovery therapy. Post-hoc analysis: ${ }^{*} \mathrm{p}<0.003$ compared to pre-intervention.

measured at the anterior thigh (left: $\mathrm{F}_{2,36}=4.404, \mathrm{p}=0.019$, $\eta^{2}=0.194$; right: $\left.F_{2,36}=7.542, p=0.002, \eta^{2}=0.284\right)$, anterior leg (left: $\mathrm{F}_{2,36}=1.772, \mathrm{p}=0.003, \eta^{2}=0.249$; right: $\left.\mathrm{F}_{2,36}=7.697, \mathrm{p}=0.002, \eta^{2}=0.258\right)$, as well as posterior right leg $\left(\mathrm{F}_{2,36}=4.200, \mathrm{p}=0.023, \eta^{2}=0.153\right)$. In general, the maximal skin temperature for those regions were larger for the ART than the INPT group but also it tended to increase in the ART but to decrease in the INPT group throughout the timing of measurements. In the absence of statistical evidence for interaction effects, significant main effects for group were observed for the maximum skin temperature measured at the posterior thigh (left: $\mathrm{F}_{1,18}=24.750, \mathrm{p}<0.001, \eta^{2}=0.579$; right: $\mathrm{F}_{1,18}=20.680$, $\left.\mathrm{p}<0.001, \eta^{2}=0.535\right)$, posterior left leg $\left(\mathrm{F}_{1,18}=13.930\right.$, $\mathrm{p}=0.002, \eta^{2}=0.436$ ), and knee (left: $\mathrm{F}_{1,18}=20.070$, $\mathrm{p}<0.001, \eta^{2}=0.527$; right: $\mathrm{F}_{1,18}=15.000, \mathrm{p}<0.001$, $\left.\eta^{2}=0.455\right)$. Conversely, significant main effects for timing of measurement were observed only for the maximum skin temperature at the posterior left leg $\left(\mathrm{F}_{2,36}=4.876\right.$, $\left.\mathrm{p}=0.013, \eta^{2}=0.195\right)$. 
Table 5. Mean values of skin temperature $\left({ }^{\circ} \mathrm{C}\right)$ of thigh, leg, and knee in elite soccer players $(\mathrm{n}=10$ per group)

\begin{tabular}{|c|c|c|c|c|c|}
\hline Body regions of interest & & $\begin{array}{c}\text { Pre- } \\
\text { intervention }\end{array}$ & $\begin{array}{l}\text { Post- } \\
\text { intervention }\end{array}$ & $\begin{array}{l}\text { 24h Post- } \\
\text { intervention }\end{array}$ & Main and interaction effects \\
\hline \multirow[t]{3}{*}{ Anterior thigh left } & & & & & Interaction: $\mathrm{F}_{2,36}=.900, \mathrm{p}=.415, \eta^{2}=.045$ \\
\hline & INPT & $31.6 \pm 0.7$ & $31.4 \pm 0.8$ & $31.8 \pm 0.7$ & Group: $\mathrm{F}_{1,18}=18.250, \mathrm{p}<.001, \eta^{2}=.503$ \\
\hline & ART & $32.3 \pm 0.9$ & $32.6 \pm 0.3$ & $32.7 \pm 0.4$ & Timing: $F_{2,36}=1.265, p=.294, \eta^{2}=.063$ \\
\hline \multirow[t]{3}{*}{ Anterior thigh right } & & & & & Interaction: $\mathrm{F}_{2,36}=1.249, \mathrm{p}=.299, \eta^{2}=.061$ \\
\hline & INPT & $31.6 \pm 0.7$ & $31.4 \pm 0.8$ & $31.7 \pm 0.8$ & Group: $\mathrm{F}_{1,18}=15.220, \mathrm{p}<.001, \eta^{2}=.458$ \\
\hline & ART & $32.3 \pm 1.1$ & $32.6 \pm 0.5$ & $32.7 \pm 0.4$ & Timing: $F_{2,36}=1.211, p=.310, \eta^{2}=.059$ \\
\hline \multirow[t]{3}{*}{ Posterior thigh left } & & & & & Interaction: $\mathrm{F}_{2,36}=1.298, \mathrm{p}=.285, \eta^{2}=.066$ \\
\hline & INPT & $31.8 \pm 0.9$ & $31.6 \pm 0.8$ & $31.8 \pm 0.7$ & Group: $\mathrm{F}_{1,18}=11.800, \mathrm{p}=.003, \eta^{2}=.396$ \\
\hline & ART & $32.2 \pm 0.7$ & $32.5 \pm 0.4$ & $32.6 \pm 0.3$ & Timing: $F_{2,36}=.494, p=.614, \eta^{2}=.025$ \\
\hline \multirow[t]{3}{*}{ Posterior thigh right } & & & & & Interaction: $\mathrm{F}_{2,36}=6.725, \mathrm{p}=.003, \eta^{2}=.199$ \\
\hline & INPT & $32.4 \pm 0.6$ & $31.4 \pm 0.8$ & $31.7 \pm 0.8$ & Group: $F_{1,18}=4.889, p=.040, \eta^{2}=.214$ \\
\hline & ART & $32.4 \pm 0.8$ & $32.3 \pm 0.7$ & $32.6 \pm 0.4$ & Timing: $\mathrm{F}_{2,36}=9.045, \mathrm{p}<.001, \eta^{2}=.268$ \\
\hline \multirow[t]{3}{*}{ Anterior leg left } & & & & & Interaction: $\mathrm{F}_{2,36}=3.178, \mathrm{p}=.034, \eta^{2}=.131$ \\
\hline & INPT & $31.7 \pm 0.8$ & $30.7 \pm 0.7$ & $31.5 \pm 0.5^{*}$ & Group: $\mathrm{F}_{1,18}=28.550, \mathrm{p}<.001, \eta^{2}=.613$ \\
\hline & ART & $32.1 \pm 0.9$ & $32.1 \pm 0.4$ & $32.5 \pm 0.3^{*}$ & Timing: $\mathrm{F}_{2,36}=6.740, \mathrm{p}=.003, \eta^{2}=.237$ \\
\hline \multirow[t]{3}{*}{ Anterior leg right } & & & & & Interaction: $\mathrm{F}_{2,36}=1.933, \mathrm{p}=.159, \eta^{2}=.070$ \\
\hline & INPT & $31.6 \pm 0.9$ & $30.8 \pm 0.8$ & $31.6 \pm 0.6^{*}$ & Group: $\mathrm{F}_{1,18}=28.680, \mathrm{p}<.001, \eta^{2}=.614$ \\
\hline & ART & $32.3 \pm 0.7$ & $32.1 \pm 0.5$ & $32.6 \pm 0.3^{*}$ & Timing: $\mathrm{F}_{2,36}=7.834, \mathrm{p}<.001, \eta^{2}=.282$ \\
\hline \multirow[t]{3}{*}{ Posterior leg left } & & & & & Interaction: $\mathrm{F}_{2,36}=1.140, \mathrm{p}=.331, \eta^{2}=.047$ \\
\hline & INPT & $31.5 \pm 0.7$ & $30.9 \pm 0.7$ & $31.4 \pm 0.6$ & Group: $\mathrm{F}_{1,18}=15.800, \mathrm{p}<.001, \eta^{2}=.467$ \\
\hline & ART & $31.9 \pm 0.6$ & $31.7 \pm 0.7$ & $32.3 \pm 0.3$ & Timing: $\mathrm{F}_{2,36}=4.883, \mathrm{p}=.013, \eta^{2}=.203$ \\
\hline \multirow[t]{3}{*}{ Posterior leg right } & & & & & Interaction: $\mathrm{F}_{2,36}=1.733, \mathrm{p}=.191, \eta^{2}=.066$ \\
\hline & INPT & $31.6 \pm 0.8$ & $30.7 \pm 0.6$ & $31.4 \pm 0.7^{*}$ & Group: $\mathrm{F}_{1,18}=15.670, \mathrm{p}<.001, \eta^{2}=.465$ \\
\hline & ART & $32.0 \pm 0.6$ & $31.7 \pm 0.7$ & $32.2 \pm 0.4^{*}$ & Timing: $\mathrm{F}_{2,36}=6.602, \mathrm{p}=.004, \eta^{2}=.251$ \\
\hline \multirow[t]{3}{*}{ Anterior knee left } & & & & & Interaction: $\mathrm{F}_{2,36}=.396, \mathrm{p}=.676, \eta^{2}=.017$ \\
\hline & INPT & $30.4 \pm 1.0$ & $29.9 \pm 0.8$ & $30.6 \pm 1.0$ & Group: $\mathrm{F}_{1,18}=10.750, \mathrm{p}=.004, \eta^{2}=.374$ \\
\hline & ART & $31.1 \pm 1.1$ & $31.0 \pm 0.7$ & $31.7 \pm 0.5$ & Timing: $\mathrm{F}_{2,36}=5.409, \mathrm{p}=.009, \eta^{2}=.227$ \\
\hline \multirow[t]{3}{*}{ Anterior knee right } & & & & & Interaction: $F_{2,36}=.244, p=.785, \eta^{2}=.012$ \\
\hline & INPT & $30.4 \pm 1.2$ & $30.0 \pm 0.7$ & $30.5 \pm 1.1$ & Group: $\mathrm{F}_{1,18}=11.610, \mathrm{p}=.003, \eta^{2}=.392$ \\
\hline & ART & $31.3 \pm 1.2$ & $31.2 \pm 0.8$ & $31.7 \pm 0.5$ & Timing: $\mathrm{F}_{2,36}=2.420, \mathrm{p}=.103, \eta^{2}=.117$ \\
\hline
\end{tabular}

INPT: intermittent negative pressure therapy; ART: active recovery therapy. Post-hoc analysis: ${ }^{*} \mathrm{p}<0.003$ compared to pre-intervention.

The two-way ANOVA showed interaction effects group by timing for the mean skin temperature measured at the posterior right thigh $\left(\mathrm{F}_{2,36}=6.725, \mathrm{p}=0.003\right.$, $\left.\eta^{2}=0.199\right)$ and anterior left leg $\left(\mathrm{F}_{2,36}=3.178, \mathrm{p}=0.034\right.$, $\left.\eta^{2}=0.131\right)$. In general, the mean skin temperature for those regions were larger for the ART than the INPT group and tended to decrease from pre- to post-intervention and to increase again from post- to $24 \mathrm{~h}$ post-intervention. In the absence of statistical evidence for interaction effects, significant main effects for group were observed for the mean skin temperature measured at the anterior thigh (left: $\mathrm{F}_{1,18}=18.250, \mathrm{p}<0.001, \eta^{2}=0.503$; right: $\mathrm{F}_{1,18}=15.220$, $\left.\mathrm{p}<0.001, \eta^{2}=0.458\right)$, posterior left thigh $\left(\mathrm{F}_{1,18}=11.800\right.$, $\left.\mathrm{p}=0.003, \eta^{2}=0.396\right)$, anterior right leg $\left(\mathrm{F}_{1,18}=28.680\right.$, $\mathrm{p}<0.001, \eta^{2}=0.614$ ), posterior leg (right: $\mathrm{F}_{1,18}=15.800$, $\mathrm{p}<0.001, \eta^{2}=0.467$; left: $\mathrm{F}_{1,18}=15.670, \mathrm{p}<0.001$, $\eta^{2}=0.465$ ), and knee (right: $\mathrm{F}_{1,18}=10.750, \mathrm{p}=0.004$, $\eta^{2}=.374$; left: $\left.\mathrm{F}_{1,18}=11.610, \mathrm{p}=0.003, \eta^{2}=0.392\right)$. Conversely, significant main effects for timing of measurement were observed only for the mean skin temperature at the 
posterior left leg $\left(\mathrm{F}_{2,36}=4.883, \mathrm{p}=0.013, \eta^{2}=0.203\right)$ and anterior left knee $\left(\mathrm{F}_{2,36}=5.409, \mathrm{p}=0.009, \eta^{2}=0.227\right)$.

\section{Discussion}

This study compared the effects of INPT vs. ART in postmatch physiological parameters serum CK level and skin temperature of the lower limbs in elite soccer players. Our findings support the original hypothesis that INPT would improve the recovery from physical stress (physiological changes in biochemical markers and thermal images). No studies were found that evaluated the impact of INPT on serum CK level and profile of thermal images in elite soccer players $24 \mathrm{~h}$ and $48 \mathrm{~h}$ after a match. Notable results from the present study showed that INPT contributed a decrease in serum CK level of $62.4 \%$ immediately after the intervention and $61 \%$ at $24 \mathrm{~h}$ after the intervention compared to ART. On the other hand, the major finding herein was that all ROI investigated in this study showed a significant decrease of the thermal images immediately after the intervention and $24 \mathrm{~h}$ after the intervention using INPT compared to ART (Tables 4 and 5). The present study also revealed no significant difference between sides in lower limbs (left vs. right), which suggests that volunteers had the same homogeneity status. Different recovery strategies such as hydrotherapy, compression garments, and active recovery are now routinely implemented by team sports athletes after a competition [14]. However, considering that CK levels and skin temperature are increased after soccer matches by climate change, grass height, stress, and high muscle fiber recruitment during matches, we can accept our hypothesis that INPT improves neuromuscular recovery after a match.

Increased intensity of efforts leads to muscle cell disturbance and delays the appearance of a CK serum peak compared to less disruption and may be linked to the time course of inflammation [7]. Hence, intense exercise contributes to damage within the structure of skeletal muscle cells at the level of the sarcolemma, alters the muscle cell permeability, causes myofilament disorganization and loss of Z-disc integrity and leads to cellular protein leakage, ultimately increasing the serum activity of many enzymes such as an increase in total CK $[9,24]$. Thus, greater recruitment of fast-twitch fibers during high-intensity exercise is reported to contribute to an increase in serum CK [24] and rating of perceived exertion (RPE) [13]. On the other hand, some studies demonstrate that an increased lower limb force is related to reduced levels of CK $>48 \mathrm{~h}$ post-match and full recovery of serum CK levels at $72 \mathrm{~h}$ post-match $[13,29]$. Our results verified that serum CK levels in INPT showed a reduction of $12.9 \%$ and $49.5 \%$ immediately post-intervention and $24 \mathrm{~h}$ post-intervention, respectively, compared to $24 \mathrm{~h}$ post-match. However, ART showed an increase of $21 \%$ in the serum CK levels immediately post-intervention and a decrease of $10 \% 24 \mathrm{~h}$ post-intervention in relation to values of $24 \mathrm{~h}$ post-match.

Contrary to our results, another study induced muscle damage using 50 drop jumps and 50 legs curls which observed a peak increase in CK at 96 hours compared to the peak 24 hours after the exercises in control and INPT groups [15]. This behavior of serum CK level may be related to the population of the study as they investigated healthy young female adults involved in moderate physical activity (not athletes) and therapy lasted for 60 minutes with hypobaric pressure variation of $4.5 \mathrm{mmHg}$ at $45 \mathrm{mmHg}$ every $20 \mathrm{sec}-$ onds [15]. In addition, a strong relationship has been observed whereby estrogen could affect muscle recovery [37]. However, INPT could improve recovery by limiting the loss in muscle strength and power and limiting the presence of pain [15]. Furthermore, some studies showed that ART had no effects on the recovery pattern of physical performance markers [3, 4]. A mechanism proposed for improvement of the recovery process using INPT involves reduction in the structural damage associated with leukocyte infiltration, consequently stabilizing the cell membrane during the process of repair, which explains the lower response of CK (the release of CK is attenuated as a result of negative pressure), and the greater venous return could improve the removal of myofibrillar proteins and other products due to the greater venous return [7, 21, 24, 30].

Considering that $\mathrm{CK}$ levels increase after soccer matches, applying two methods for muscle activity assessment are more accurate [17]. Thus, the use of thermal images combined with serum CK level can together determine muscle damage, because only biochemical markers do not show the anatomical location of the muscle injury and both methods can provide rapid feedback for coaches during training phases. However, the elevated skin temperatures found 24 to 72 hours after exercise in all participants is possibly the result of higher blood flows in muscle due to inflammation, and tissue damage repair [2]. Indeed, thermal image changes can be related to higher workout intensity and morphological changes in muscle tissue by modifying the cross-sectional area of the muscle $[16,38]$. This response reveals that trained participants have a higher cutaneous blood flow than others by several physiological changes (e.g., increased muscle metabolism, anaerobic energy reserve, density of capillaries, nerve conduction rate and morphological changes in muscle tissue by modifying the cross-sectional area of the muscle) $[1,16,25,38]$. A recent study published by our research group showed that thermal symmetry of the lower limbs was similar between the sides of the body at rest in elite soccer players, being identical in shape and size [25]. In the present study, evaluated elite soccer players showed contralateral thermal symmetry in both groups (INPT and ART) and all the ROI were not greater than $0.2^{\circ} \mathrm{C}$. On the other hand, our results showed differences between groups in maximal and mean 
values $>0.7^{\circ} \mathrm{C}$ immediately post-intervention and $24 \mathrm{~h}$ post-intervention in front and back lower limbs in which a differences in thermal image $\left(>0.7^{\circ} \mathrm{C}\right)$ can be associated with structural or physiological abnormalities that contribute to a decrease in the quadriceps power $[25,39]$. These differences $>0.7^{\circ} \mathrm{C}$ in the skin temperature between elite soccer players (INPT vs. ART) possibly by INPT contribute to the process of recovery from the increased blood flow in the microcirculation, reduction of edema, removal of exudate, cell proliferation and angiogenesis, which can lead to faster neuromuscular recovery, reduced muscle tension, and reduced pain sensation $[6,15]$.

A limitation of this type of investigation could be the specific position of the soccer players, climatic conditions and condition of the grass during the soccer match since these parameters could influence serum CK level, skin temperature measurements, and autonomic response. While our sample was homogeneous, the sample size was not large enough to provide variations in physiological condition to specific positions. Future research should elucidate the influence of the external training load in the biochemical markers during training and/or matches in elite soccer players.

\section{Conclusions}

Serum CK level and skin temperature of lower limbs showed better recovery up to $24 \mathrm{~h}$ post-intervention using INPT in elite soccer players. It is recommended to use such a passive recovery strategy over ART the day after a game as the latter might be counterproductive to the recovery process.

Practical applications

- INPT is a new approach to design and optimize the time of recovery in elite soccer players. Thus, coaches should consider these data when planning workouts and training after matches and monitor recovery to ensure optimal performance during competitions.

- INPT may have beneficial effects for post-matches recovery because of the decreasing serum CK level and skin temperature of lower limbs.

- We recommend that future studies should be performed to clarify the mechanisms associated with the recovery process in elite soccer players.

Conflict of interest: Authors state no conflict of interest.

\section{References}

1. Abate M., Di Carlo L., Di Donato L., Romani G.L., Merla A. (2013) Comparison of cutaneous termic response to a standardized warm up in trained and untrained individuals. J. Sports Med. Phys. Fitness, 53: 209-215.
2. Al-Nakhli H.H., Petrofsky J.S., Laymon M.S., Berk L.S. (2012) The use of thermal infra-red imaging to detect delayed onset muscle soreness. J. Vis. Exp., 59: pii: 3551.

3. Andersson H., Bøhn S.K., Raastad T. (2010) Differences in the inflammatory plasma cytokine response following two elite female soccer games separated by a 72-h recovery. Scand. J. Med. Sci. Sports., 20: 740-747.

4. Andersson H., Raastad T., Nilsson J. (2008) Neuromuscular fatigue and recovery in elite female soccer: effects of active recovery. Med. Sci. Sports Exerc., 40: 372-380.

5. Anghel E.L, Kim P.J, Attinger C.E. (2016) A solution for complex wounds: the evidence for negative pressure wound therapy with instillation. Int. Wound J., 13: 19-24.

6. Arvesen K., Nielsen C.B., Fogh K. (2017) Accelerated wound healing with combined NPWT and IPC: a case series. Br. J. Community Nurs. Suppl 3: S41-S45.

7. Baird M.F., Graham S.M., Baker J.S., Bickerstaff G.F. (2012) Creatine-kinase-and exercise-related muscle damage implications for muscle performance and recovery. $J$. Nutr. Metab., 2012: 960363. DOI: 10.1155/2012/960363.

8. Baldwin C., Potter M., Clayton E., Irvine L., Dye J. (2009) Topical negative pressure stimulates endothelial migration and proliferation: a suggested mechanism for improved integration of Integra. Ann. Plast. Surg., 62: 92-96.

9. Brancaccio P., Maffulli N., Limongelli F.M. (2007) Creatine kinase monitoring in sport medicine. Br. Med. Bull., 81-82: 209-230.

10. Casamichana D., Castellano J., Calleja-Gonzalez J., San Román J., Castagna C. (2013) Relationship between indicators of training load in soccer players. J. Strength Cond. Res., 27: 369-374.

11. Chaouachi A., Manzi V., Chaalali A., Wong del P., Chamari K. (2012) Determinants analysis of change-ofdirection ability in elite soccer players. J. Strength Cond. Res., 26: 2667-2676.

12. Dalen T., Ingebrigtsen J., Ettema G., Hjelde G.H., Wisløff U. (2016) Player load, acceleration, and deceleration during forty-five competitive matches of elite soccer. $J$. Strength Cond. Res., 30: 351-359.

13. Djaoui L., Diaz-CidonchaGarcia J., Hautier C., Dellal A. (2016) Kinetic Post-match Fatigue in Professional and Youth Soccer Players During the Competitive Period. Asian J. Sports Med., 7: e28267.

14. Doeven S.H., Brink M.S., Kosse S.J. (2018) Postmatch recovery of physical performance and biochemical markers in team ball sports: a systematic review. BMJ Open Sport Exerc. Med., 4: e000264.

15. Fonda B., Sarabon N. (2015) Effects of intermittent lower-body negative pressure on recovery after exerciseinduced muscle damage. Int. J. Sports Physiol. Perform., 10: 581-586.

16. Formenti D., Ludwig N., Gargano M., Gondola M., Dellerma N., Caumo A., Alberti G. (2013) Thermal imaging 
of exercise-associated skin temperature changes in trained and untrained female participants. Ann. Biomed. Eng., 41: 863-871.

17. Harper L.D., Hunter R., Parker P., Goodall S., Thomas K., Howatson G., West D.J., Stevenson E., Russell M. (2016) TestRetest Reliability of Physiological and Performance Responses to 120 Minutes of SimulatedSoccer Match Play. J. Strength Cond. Res., 30: 3178-3186.

18. Jones C.M., Griffiths P.C., Mellalieu S.D. (2017) Training Load and Fatigue Marker Associations with Injury and Illness: A Systematic Review of Longitudinal Studies. Sports Med., 47: 943-974.

19. Kim P.J., Applewhite A., Dardano A.N., Fernandez L., Hall K., McElroy E., Mendez-Eastman S., Obst M.A., Thomas C., Waddell L., Wirth G., Téot L. (2018) Use of a novel Foam Dressing with Negative Pressure Wound Therapy and Instillation: Recommendations and Clinical Experience. Wounds., 30: S1-S17.

20. Kinugasa T., Kilding A.E. (2009) A comparison of postmatch recovery strategies in youth soccer players. $J$. Strength Cond. Res., 23: 1402-1407.

21. Kraemer W.J., French D.N., Spiering B.A. (2004) Compression in the treatment of acute muscle injuries in sport: Review article. Int. Sport Med. J., 5: 200-208.

22. Langfitt M., Webb L.X., Onwuchuruba C., Callahan M., Smith T.L. (2013) Microvascular effects of subatmospheric pressure in striated muscle. J. Reconstr. Microsurg., 29: 117-123.

23. Loose O., Achenbach L., Fellner B., Lehmann J., Jansen P., Nerlich M., Angele P., Krutsch W. (2018) Injury prevention and return to play strategies in elite football: no consent between players and team coaches. Arch. Orthop. Trauma Surg., 138: 985-992.

24. Magal M., Dumke C.L., Urbiztondo Z.G., Cavill M.J., Triplett N.T., Quindry J.C. (2010) Relationship between serum creatine kinase activity following exerciseinduced muscle damage and muscle fiber composition. J. Sports Sci., 28: 257-266.

25. Maior A.S., Leporace G., Tannure M., Marocolo M. (2017) Profile of infrared thermography in elite soccer players. Motriz: Rev. Educ. Fis., 23: 1-6.

26. Mansfield C.J., Ferkovic-Mack C., Eibensteiner J. (2018) A review advocating caution with Major League Soccer expansion and investment in more rehabilitation professionals. Phys. Ther. Sport, 37: 190-196.

27. Nédélec M., Halson S., Delecroix B., Abaidia A.E., Ahmaidi S., Dupont G. (2015) Sleep Hygiene and Recovery Strategies in Elite Soccer Players. Sports Med., 45: 1547-1559.

28. Nédélec M., McCall A., Carling C., Legall F., Berthoin S., Dupont G. (2013) Recovery in soccer : part ii-recovery strategies. Sports Med., 43: 9-22.

29. Owen A., Dunlop G., Rouissi M., Chtara M., Paul D., Zouhal H., Wong del P. (2015) The relationship between lowerlimb strength and matchrelated muscle dam- age in elite level professional European soccer players. $J$. Sports Sci., 33: 2100-2105.

30. Paulsen G., Benestad H.B., Strøm-Gundersen I., MørkridL., Lappegård K.T., Raastad T. (2005) Delayed leukocytosis and cytokine response to high-force eccentric exercise. Med. Sci. Sports Exerc., 37: 1877-1883.

31. Pfirrmann D., Herbst M., Ingelfinger P., Simon P., Tug S. (2016) Analysis of Injury Incidences in Male Professional Adult and Elite Youth Soccer Players: A Systematic Review. J. Athl. Train., 51: 410-424.

32. Ranchordas M.K., Dawson J.T., Russell M. (2017) Practical nutritional recovery strategies for elite soccer players when limited time separates repeated matches. J. Int. Soc. Sports Nutr., 14: 35.

33. Schwellnus M., Soligard T., Alonso J.M., Bahr R., Clarsen B., Dijkstra H.P. (2016) How much is too much?(Part 2) International Olympic Committee consensus statement on loadin sport and risk of illness. Br. J. Sports Med., 50: 1043-1052.

34. Sundby Ø.H., Høiseth L.Ø., Mathiesen I., Jørgensen J.J., Weedon-Fekjær H., Hisdal J. (2016) Application of intermittent negative pressure on the lower extremity and its effect on macro - and microcirculation in the foot of healthy volunteers. Physiol. Rep., 4: e12911.

35. Sundby Ø.H., Høiseth L.Ø., Mathiesen I., WeedonFekjær H., Sundhagen J.O., Hisdal J. (2017)The acute effects of lower limb intermittent negative pressure on foot macroand microcirculation in patients with peripheral arterial disease. PLoS One., 12: e0179001.

36. Taylor J.M., Macpherson T.W., McLaren S.J., Spears I., Weston M. (2016) Two Weeks of Repeated-Sprint Training in Soccer: To Turn or Not to Turn? Int. J. Sports Physiol. Perform., 11: 998-1004.

37. Tiidus P.M. (2000) Estrogen and gender effects on muscle damage, inflammation, and oxidative stress. Can. J. Appl. Physiol., 25: 274-287.

38. Trecroci A., Formenti D., Ludwig N., Gargano M., Bosio A., Rampinini E., Alberti G. (2018) Bilateral asymmetry of skin temperature is not related to bilateral asymmetry of crank torque during an incremental cycling exercise to exhaustion. Peer J., 6: e4438.

39. Vedran Hadžić B.Š., Aleš M., Milan Č. (2019) Can infrared thermography be used to monitor fatigue during exercise? A case study. J. Sport. Health Sci., 8: 89-92.

\section{Received 13.11.2019 \\ Accepted 15.02.2020}

(C) University of Physical Education, Warsaw, Poland

\section{Acknowledgments}

This study was supported by the Coordenação de Aperfeiçoamento de Pessoal de Nível Superior - Brasil (CAPES) - Finance Code 001. 